\title{
PROYECCIONES DE LA BUENA FE EN EL DERECHO TRIBUTARIO: UNA MIRADA DESDE LA JURISPRUDENCIA URUGUAYA
}

THE INFLUENCE OF THE BONA FIDES PRINCIPLE IN TAX LAW: AN APPROACH FROM THE URUGUAYAN CASE LAW

\author{
Jonás Bergstein* \\ Universidad de la República \\ Bergstein Abogados
}

\begin{abstract}
Although the Bona Fides principle may appear to be an ambiguous or inconclusive definition at first instance, examination of its correct applicability is considerably relevant when determining a standard of conduct for taxpayers. Indeed, it is peaceful to recognise the transversality the Bona Fides has among all fields of the legal system. However, the question of its integrated realisation in tax law remains unresolved.

In this paper, the author recommends some categories to analyse the values that inspire the principle in practice. To achieve this, the settled case law of the Uruguayan Administrative Dispute Tribunal (TCA in Spanish) is accurately revised and compared with legal literature to attain some carefully thought-out conclusions.
\end{abstract}

KEYWORDS: Bona Fides principle; Tax Administration; taxpayer; administrative law.
A pesar de que el Principio de Buena Fe pueda parecer, a primera vista, difuso o incompleto para el Derecho, el análisis de su correcta aplicación es de trascendental importancia para establecer un estándar de conducta a los contribuyentes. Particularmente, es pacífico el reconocimiento de la Buena Fe en todos los campos del sistema jurídico. No obstante, la cuestión de su adecuada realización en el Derecho Tributario permanece no resuelta.

En este artículo, el autor recomienda algunas categorías para analizar los valores que inspiran el principio en la práctica. Para ello, la jurisprudencia del Tribunal en lo Contencioso Administrativo de Uruguay (TCA) es examinada y comparada con doctrina con el propósito de arribar a algunas consideraciones rigurosamente presentadas.

PalabRas Clave: principio de buena fe; Administración tributaria; contribuyentes; derecho administrativo.

Abogado. Master of Laws (LL.M.) por la Harvard Law School. Ex asociado internacional de Wilmer, Cutler \& Pickering y de Mattos Filho e Suchodolski Advogados. Profesor de la Facultad de Derecho de la Universidad de la República. Socio de Bergstein Abogados, Montevideo, Uruguay. Contacto: jbergstein@bergsteinlaw.com.

Nota del Editor: El presente artículo fue recibido por el Consejo Editorial de THËMIS-Revista de Derecho el 18 de noviembre de 2019, y aceptado por el mismo el 20 de febrero de 2020 . 


\section{INTRODUCCIÓN: NOCIONES GENERALES}

En el estado actual de la evolución del Derecho, es pacífica la admisión de la extensión del principio de la buena fe al campo tributario. Sin embargo, parecería que aún no es explícito el alcance del principio en la materia tributaria, es decir, ¿qué aplicaciones o qué proyecciones concretas tiene el estándar de la buena fe en el campo tributario? He aquí la pregunta a la cual intentaremos dar respuesta en el presente artículo.

Mucho más que buscar una noción o concepto de la buena fe en esta materia -pues la buena fe es esquiva a las definiciones-, procuraremos establecer categorías o tipos de comportamientos esperados o modelos de referencia, a decir del uruguayo Jorge Gamarra Sagarra (2011, p. 16). A partir de ello, entendemos que la buena fe, al menos la llamada buena fe objetiva, es precisamente un padrón de comportamiento o modelo de conducta del cual se desprenden derechos, obligaciones y, especialmente, expectativas, esto es, qué conductas son esperables de un sujeto -en este caso, los contribuyentes y la Administración tributaria-, en función de las circunstancias de cada caso concreto.

La buena fe tributaria involucra una comparación de conductas, entre la conducta adoptada por el contribuyente (o la Administración) en el caso concreto y la conducta que debiera ser idealmente practicada o esperada conforme a las expectativas ordinarias en casos semejantes, de acuerdo al celo que la ocasión requiera (Torres, 2015, p. 224). Las circunstancias de tiempo y lugar adquieren un rol preponderante, pues solo a partir de ellas es posible alcanzar la justicia en el caso concreto y, asimismo, por la propia variabilidad de la noción de buena fe, que ofrece matices en función del contexto y de la cultura dominantes ${ }^{1}$ (Sepinuck, 2018, pp. 583-584). Las exigencias que la buena fe puede imponer en los tiempos actuales, con seguridad han de ser diferentes en otro tiempo y lugar (Gamarra Sagarra, 1977, p. 16).

Precisamos, además, que las proyecciones de la buena fe a las que haremos referencia más adelante, a partir de la agrupación de casos concretos, han sido ya abundantemente estudiadas en nuestro medio por la literatura administrativista. Notamos, sin embargo, que dicha revisión se ha realizado mayoritariamente desde ángulos de análisis, tales como la motivación del acto, la desviación de poder, la celeridad del procedimiento, el debido procedimiento, el informalismo en favor del administrado ${ }^{2}$, entre otros institutos particularmente útiles en el ámbito del derecho administrativo.

La buena fe no viene a desplazarlos ni tampoco a ocupar su lugar, al punto que el artículo 2 del Decreto 500, Aprobación del Procedimiento Administrativo y Disciplinario Aplicable al Funcionario Público de La Administración Central en Uruguay, enumera unos y otros. De hecho, el sustrato de esas figuras es compartido con la buena fe, que privilegia la rectitud y coherencia del comportamiento, la conducta transparente y proactiva.

Al analizar los casos en las categorías que hemos agrupado, es evidente que en muchos de ellos la buena fe logrará suplir o aportar algún ingrediente adicional allí donde aquellas figuras del derecho administrativo no puedan llegar o resulten insuficientes; o bien, ratificará la solución a la cual se arriba a través de los institutos mencionados que, como decíamos, se encuentran ya largamente decantados en el pensamiento administrativista y en la jurisprudencia uruguaya. Así, la motivación del acto, o la necesidad de dar vista previa, son habitualmente enfocadas desde la óptica del derecho de defensa, pero ambas son también expresión de la buena fe y, en particular, de una de sus acepciones: la transparencia.

Como veremos, esas figuras permanecen iguales. La buena fe quizás permita, con un poco de fortuna, y dependiendo siempre de las circunstancias del caso, arrojar una mirada distinta, que en muchos casos podrá aportar la solución del caso -allí donde no haya regla ni otros institutos directamente aplicables- , y en tantos otros, por fin, no habrá más que ratificar la conclusión a la cual se arriba. En este sentido, justo es reconocer que, si alguna singularidad pudiera atribuírsele a este estudio, no es otra que la peculiaridad de su enfoque; esto es, agrupar o nuclear esas sentencias bajo una unidad conceptual diversa: la buena fe.

\section{LA TIPOLOGÍA: CONSIDERACIONES GENE- RALES}

Todos reconocemos que la buena fe, en cuanto principio general del Derecho, encarna una serie de valores que planean el orden jurídico que, con variantes, son unánimemente reconocidos por todos los autores. Así, es un lugar común la

\footnotetext{
La íntima conexión de la buena fe con las circunstancias del caso concreto es también subrayada en el Derecho norteamericano (donde la buena fe no tiene el alcance de que goza en nuestro medio). Sobre el particular, véase Sepinuck, S. (2018).

2 En ese sentido, véase por todos, Delpiazzo, C. (2011a, pp. 324 y ss.).
} 
referencia a la honestidad, probidad, sinceridad, confianza mutua, lealtad, responsabilidad, solidaridad, previsibilidad del orden jurídico, fidelidad y cohesión social, por citar los más frecuentemente nombrados ${ }^{3}$.

También es útil hablar de los denominados disvalores o contravalores, pues nos ayudan a visualizar el valor en toda su dimensión y en su cabal sentido: insinceridad, deslealtad, deshonestidad, irresponsabilidad, infidelidad, entre otros. Muchas veces identificamos la transgresión del estándar que nos convoca tras identificar el disvalor de la conducta.

Son frecuentes las invocaciones a la buena fe y las referencias a la lealtad, honestidad y probidad que ella implica. Por ello, es de estilo que las normas de procedimiento administrativo-tributario incluyan una referencia expresa a la buena fe dentro del elenco de principios rectores del procedimiento tributario. Menos frecuente, en cambio, es el aterrizaje o concretización, es decir, ese salto adicional que permite inferir, por ejemplo, que la buena fe proscribe denominar acta final de inspección a un documento que no reúna las características de ese instituto, o que el uso de estratagemas artificiosos que abusan de las formas jurídicas es inoponible al fisco porque la buena fe veda el fraude a la ley fiscal. Es necesario concretar estos valores en términos tangibles pues, como decía Larenz, la buena fe necesita de concreción (1985, pp. 97-98).

Doctrinariamente, la referencia a la concretización de este principio es casi una constante (Gamarra Sagarra, 2011, p. 14). En Uruguay se ha se expresado con singular claridad:

Habitualmente se enseña que debe entenderse por buena fe "la conducta leal, honesta, correcta, escrupulosa, incluso solidaria". Pero esto no es suficiente; lo que importa es precisar cuándo un contratante actúa lealmente, y aquí la fuente decisiva es el "derecho vivo", esto es, las sentencias judiciales (Gamarra Sagarra, 2009, p. 935).
Como puntos de referencia para nuestro análisis emplearemos grupos de casos. Estos han sido seleccionados en la medida en que reflejan una aplicación jurisdiccional reiterada del principio a situaciones similares o análogas, por lo que son idóneos para construir categorías de conductas esperadas ${ }^{4}$.

Esos conjuntos de casos debieran servir, de un lado, para asistir al juez en su labor y, al mismo tiempo, establecer un freno para contener la inevitable discrecionalidad del juez a la hora de aplicar un concepto jurídico indeterminado como la buena fe (González Méndez, 2001, p. 149). Si se acepta -como lo hace un amplio espectro de la literatura comparada- que la buena fe es la herramienta que la jurisprudencia ha encontrado a la hora de buscar una solución justa, allí donde esta no habría sido factible sin una dosis de dulcificación en la aplicación de las normas ${ }^{5}$, ha de convenirse que la búsqueda de esa solución justa debe ser jurídica y, como tal, enmarcarse en los carriles propios de la disciplina que cultivamos.

En esta línea se ubica, creemos, el pensamiento del juez uruguayo Leslie Van Rompaey, quien afirma que "el instrumento más fructífero para lograr la justificación del caso concreto, lo conforman los principios generales de derecho"6 (2000, p. 731). Todo ello -agrega el autor- sin caer en las soluciones contra legem, ni en el desenfrenado arbitrio judicial, ni en una suerte de escuela libre del Derecho (2000, p. 730). Consideraciones que suscribimos en todos sus términos. He aquí expuesta la tarea que nos hemos impuesto en este análisis.

Esa agrupación de casos es posible precisamente porque detrás de todas las manifestaciones o expresiones de la buena fe que habremos de reseñar, subyace, en mayor o menor medida, una nota común: un juicio de reprochabilidad, un obrar torcido, avieso, desleal, reticente o poco transparente, a veces irrazonable, o al menos contrario a la finalidad de la norma o a la conducta que se espera del sujeto con quien se ha entrado en relación, llámese Administración, llámese contribuyente.

3 Ferreira Rubio recuerda que los principios generales son una de las formas de manifestación de los valores. Señala que en el camino hacia la concreción técnica los principios generales serían algo así como la primera envoltura externa de los valores (1984, p. 122).

4 Gamarra Sagarra enseña que son siempre "los Jueces los que realizan la concreción de la moral [...] pero ni los Jueces ni la doctrina quedan conformes con ello y por ello buscan un marco que sea menos amplio e indeterminado" (2011, p. 29).

5 Un ejemplo permitirá ilustrar el punto. Supóngase el caso de un contribuyente que a la hora de pagar un impuesto por una cuantía varias veces millonaria, omite pagar (el importe total) la suma de \$1. Creemos que si no apelamos al principio de la buena fe -en alguna o algunas de sus manifestaciones, en especial, la razonabilidad-, no será posible alcanzar la solución justa al caso concreto (y en su mérito será menester tipificar la infracción de mora con la correspondiente multa y recargos. Solución que a nuestro juicio luce injusta). Ejemplos similares son convocados por González Méndez en su enjundiosa monografía (2001, p. 175).

$6 \quad$ Una reflexión similar puede encontrarse en el pensamiento de Torres en Brasil, en el ámbito propiamente tributario: "la confianza funcional asume el papel de promover la justicia en situaciones concretas en las cuales ni la legalidad ni la previsibilidad del ordenamiento han sido capaces de garantizarla" (2015, p. 227). 
En la inmensa mayoría de los casos relevados, el transgresor de la buena fe procura, mucho más que actuar la ley o cumplir sus obligaciones, prevalecer en el litigio (cuando no violentar la ley). ¿Cómo lo sabemos? Atendiendo a la motivación, a los móviles que hay detrás de la conducta o del acto en cuestión: es el descubrimiento del propósito que se esconde detrás de la conducta -naturalmente exteriorizado a través de signos o manifestaciones externas-, el que habrá de echar luz e iluminar el juicio de reprochabilidad ${ }^{7}$. Todo ello sin perder de vista que, con singular frecuencia, los institutos jurídicos aparecen entrelazados unos y otros, de modo que rara vez la buena fe se presenta de manera aislada o en estado de pureza ${ }^{8}$.

Como se comprenderá, la buena fe tributaria es un camino de ida y vuelta, que obliga tanto a los particulares como a la Administración ${ }^{9}$. Hoy se acepta pacíficamente que, en una sociedad democrática y liberal, nadie puede estar excluido de la obligación de actuar de buena fe ${ }^{10}$. Ello sin perjuicio de dejar anotado que la literatura comparada dedicada al estudio de la buena fe objetiva en el terreno tributario, se ocupa mucho más de la buena fe de la Administración que de aquella que obliga a los particulares.

Dicho eso, la incidencia de la buena fe no es exactamente la misma en un sentido y otro ${ }^{11}$. Entre otros, porque existen una multiplicidad de normas que regulan la actuación del Estado en la aplicación de la norma en general y en el procedimiento administrativo en particular. También porque es el Estado quien inviste la triple calidad de creador de la norma, ejecutor, y juez. Por lo demás, si se acepta -en temperamento que compartimos- que la buena fe es el elemento tipificante del abuso de derecho propio de la planificación tributaria ilegítima, es natural que esa proyección de la buena fe imponga un estándar de conducta, es decir, un límite de actuación extensible únicamente a los contribuyentes.
Por fin, una breve reflexión en punto a las consecuencias de la transgresión del principio de la buena fe. Las implicancias jurídicas pueden ser dispares. De hecho, en la literatura especializada (iusprivatista) es frecuente hablar de una pluralidad de remedios $^{12}$. En lo que a nuestro ámbito refiere, habrá que estar a las peculiaridades del caso concreto, particularmente a la entidad del apartamiento de que se trate y a las obligaciones omitidas y/o a los derechos que se hubieren cercenado.

En cualquier caso, esas consecuencias podrán ser variables y oscilar entre la privación de efectos del acto transgresor, la reparación de los daños y perjuicios causados, la condena en costas y costos e, inclusive, la anulación del acto administrativo, conforme correspondiera ${ }^{13}$. Justo es decir que atento a un principio de trascendencia -presente también en la teoría de las nulidades en materia administrativa ${ }^{14}-$, bien podría suceder que una transgresión aislada y menor del estándar resulte inconsecuente.

Considerando que esta nota va dirigida a un auditorio internacional, prescindimos de las referencias a las sentencias del Tribunal de lo Contencioso Administrativo (en adelante, TCA) que ha servido de norte y de guía para nuestra investigación. Se trata del máximo órgano jurisdiccional que en Uruguay revisa, con carácter exclusivo y excluyente, las decisiones firmes de la Administración tributaria. Lo componen cinco ministros designados por el Poder Legislativo. En ese sentido, quiere decir que todas las proyecciones generales que abajo reseñamos encuentran cabida en la jurisprudencia reciente del TCA.

\section{TRANSPARENCIA}

La palabra tiene diversas acepciones ${ }^{15}$. La transparencia que ahora nos convoca es aquella que impone al Estado el deber de desarrollar la actividad

7 Se trata de una función análoga -si se nos permite el símil- a la que cumple la causa simulandi en materia de simulación en el derecho civil uruguayo. Enseña nuestro máximo civilista que la simulación es el móvil que explica por qué razón se recurre al procedimiento simulatorio. Al respecto, señala que es un "eficaz punto de partida para ordenar la prueba indiciaria de la simulación en torno a un núcleo central que explique el motivo que tuvieron los simulantes para recurrir a la ficción" (Gamarra Sagarra, 1979, pp. 52-53). En materia de buena fe tributaria, serán la punta de la madeja que nos permitirá explicar el conjunto de conductas que se han desplegado en contravención con el principio de la buena fe.

8 En ese sentido, véase lo señalado por Durán Martínez, A. (2010, p. 73).

9 Véase González Méndez, A. (2001, p. 163); Yersin y otros. (2007, p. 37).

10 Véase González Méndez, A. (2001, p. 163); Mairal, H. (1988, p. 52).

11 Véase Rodrigues, M. S. (2007, p. 61).

12 Véase Gamarra Sagarra, J. (2011, pp. 177 y ss.).

13 Véase González Méndez, A. (2001, p. 163); Yersin y otros (2007, p. 52; 149 y ss.).

14 En este sentido, ha sido ampliamente citado por la jurisprudencia del Tribunal de lo Contencioso Administrativo, CajarviIle Peluffo, J. P. (2007, pp. 250-252)

15 De hecho, se le vincula y se le menciona reiteradamente como un principio fundamental en el combate contra la corrupción. Tal es el caso de Ferreira Rubio, que trae a colación el informe de la Comisión Nolan en Gran Bretaña, aprobado 
financiera de acuerdo a pautas de claridad, apertura y simplicidad ${ }^{16}$. Es la proscripción de la reticencia y de la vaguedad, allí donde existe la obligación de actuar y/o hablar con escrupulosidad y cristalinidad (Gamarra Sagarra, 2011, p. 78). Es la interdicción del comportamiento omiso y la obligación de romper el mutismo allí donde el silencio -o bien la omisión o la inacción-, pueden inducir en una creencia equivocada o desembocar en una solución contraria a Derecho. Al igual que la buena fe, no se concibe un Estado de Derecho que no sea transparente. Una actuación reñida con la transparencia, resultará ineludiblemente reñida con la buena $\mathrm{fe}^{17}$, toda vez que la buena fe impone una conducta honesta, inequívoca, veraz, prístina y que no traicione la confianza razonable de la otra parte ${ }^{18}$.

Tal como se ha podido afirmar en el medio uruguayo, "Ia transparencia, la verdad y los derechos conjugan una trilogía necesaria para el cumplimiento del 'contrato social' erigido a través de la fundación del Estado en el cumplimiento de sus fines y cometidos" (Sabaris Núñez, 2017, p. 93). Si, en un Estado democrático de Derecho, la arbitrariedad está vedada, y si es correcto que su esencia es la necesidad del Estado de justificar sus decisiones y de permitir a los ciudadanos el control de su actuación, fluye que la transparencia hace a lo que hoy se denomina la calidad democrática de una nación ${ }^{19}$. Porque no puede haber un control genuino sin trasparencia de la Administración, es decir, sin una actuación que brinde los medios para ejercitar ese contralor: esto es, una actuación (como mencionamos antes) traslúcida, diáfana, libre del ardid, de medias tintas o de medias verdades, de ocultamientos y de silencios, allí donde existe la carga de hablar y de ser explícitos ${ }^{20}$. Conductas o cualidades -todas ellas-que son propias de la buena fe, invariablemente asociada a las virtudes sobre las que insiste la unanimidad de los autores ( $\mathrm{y}$ tantas veces citadas a lo largo de esta nota): sinceridad, lealtad, escrupulosidad y probidad ${ }^{21}$.

Se trata de explicar, de no ocultar eventuales carencias o errores, de no inducir en error a través del silencio o de la simple inacción (allí donde no hay razones que impongan la reserva ${ }^{22}$ ). Esto es especialmente importante cuando la información o los datos que no se dan a conocer pudieren traducirse en un resultado adverso o contrario a la pretensión o a la postura de la Administración en un determinado procedimiento (o, lo que es lo mismo, cuando sería razonable inferir que el conocimiento -por el particular- de la información silenciada habría de robustecer la pretensión de este). Y sobremanera también cuando se es consciente (o aun cuando razonablemente se debe ser consciente) de que, de no develarse el dato o la información ocultos, el resultado será contrario a Derecho $^{23}$.

por el Parlamento británico el 16 mayo 1995. El denominado Report Nolan formuló siete principios de la vida pública, a partir de los cuales propuso que se derivaran y formularan explícitamente reglas concretas de conducta. Entre esos principios se alude a la transparencia en los términos que siguen: "Los funcionarios públicos deben ser lo más transparentes posible acerca de todas sus decisiones y acciones. Deben dar fundamento de sus decisiones y restringir la información sólo cuando así lo demande un interés público superior" (Ferreira Rubio, 1984, p. 70).

16 Al respecto, veáse Lobo Torres, R. (2001, pp.153 y ss.).

17 En esta misma línea, Juan Pablo Cajarville Peluffo ha vinculado la transparencia con la buena fe. En ese sentido, véase Cajarville Peluffo, J. (2007, p. 402). Además, en su Tratado, Jorge Gamarra Sagarra ha escrito que "la regla de la buena fe impone el deber de hablar" (2006, p. 70).

18 La expresión pertenece a Cajarville Peluffo, luego de apuntar finamente la vinculación (en sede de contratación administrativa) de la buena fe con la transparencia (2007, pp. 401-402).

19 A propósito de la publicidad, hace más de 50 años Cassinelli Muñoz escribía que

[...] el buen funcionamiento de la forma republicana de gobierno exige, entre otras cosas, la información del pueblo acerca de la gestión de los gobernantes [...] la opinión pública debe tener las vías de acceso a la gestión de gobierno, para que el control popular sobre los gobernantes sea una realidad efectiva. Puede afirmarse, por ende, que el principio de la publicidad de la gestión administrativa deriva de la forma republicana de gobierno [...] (1962, pp. 162-163).

En tiempos mucho más recientes, López Rocca ha escrito que "en la democracia, el control de la gestión de los gobernantes requiere, de necesidad, la publicidad, puesto que posibilita responsabilizarlos por su gestión" (2003, p. 41).

20 Delpiazzo, citado reiteradamente por el TCA, tiene establecido que

la transparencia implica algo más que mostrar, implica dejar ver; simplemente que el actuar de la Administración se deje ver como a través de un cristal [...] la transparencia refiere a la diafanidad del obrar público [...] consecuencia de la muy elemental presunción de que el gobierno pertenece al pueblo (2003, p. 114; 2005, pp. 71-72).

21 Un comportamiento que no es transparente, es también insincero y desleal.

22 Véase Sabariz Núñez, G. (2017, p. 92).

23 En Brasil, Meigan Sack Rodrigues ha escrito lo siguiente:

[...] sería contrario a la buena fe que la Administración tuviese en su poder pruebas que beneficiasen al contribuyente y no las pusiese en su conocimiento o bien no las hiciere valer en un procedimiento relevante; inclusive (sería contrario a la buena fe) que se aprovechase del desconocimiento de éste o de sus errores, para privarle de algún derecho (2007, p. 65). 
Haciéndose eco de estos lineamientos, la jurisprudencia tributaria uruguaya ha subrayado la obligación de la Administración de identificar los índices o márgenes de utilidad aportados por terceros y utilizados por aquella. También aquel Tribunal tiene establecido que todos los elementos relevantes que han de erigirse en el sostén de la determinación, deben ser pasibles de contralor por parte del contribuyente o el responsable (en tiempo oportuno) $y$, por ende, deben haber sido incorporados al expediente administrativo previo al otorgamiento de la vista de las actuaciones.

Asimismo, la jurisprudencia uruguaya es igualmente rigurosa a la hora de exigir que los medios probatorios de que se vale la Administración sean preservados en estado de pureza. Esto es, precisamente, a efectos de garantizar que los medios de prueba no sean alterados luego de haber sido retirados por el equipo inspectivo, en términos tales que no exista la más mínima duda sobre la total genuinidad de la prueba agregada

La transparencia - y la buena fe que le subyace- se vinculan también con la necesidad de justificar la liquidación en que tanto ha insistido el Tribunal. Cuestión que hace a la motivación del acto administrativo, en la medida en que esa motivación no tiene otro sentido que explicar, echar luz, fundamentar, el actuar de la Administración, de manera que su actuación pueda estar sujeta al escrutinio de los hombres (descartando la arbitrariedad y también la inmunidad) ${ }^{24}$.

La motivación del acto administrativo es un axioma del Derecho Administrativo uruguayo, amplia y finamente decantado en la doctrina y en la jurisprudencia nacional ${ }^{25}$. Enseña Durán Martínez que "es un valor entendido que la motivación es un elemento necesario en cualquier acto administrativo y que, su ausencia, lo vicia de nulidad" (1999, p. 67). El propio TCA ha dicho con singular elocuencia, que la adecuada motivación de una decisión es lo que aleja el acto "de ser un mero acto de autoridad, conjura la arbitrariedad y permite aquilatar su racionalidad"26.
La jurisprudencia tributaria de este tribunal ha destacado la necesidad de justificar cómo se llega a la liquidación del adeudo o, para expresarlo con palabras sencillas, cómo se llega a los números de la deuda por tributos. El TCA estableció que "la motivación del acto conjura la arbitrariedad, aleja la actuación de la Administración del mero acto de autoridad, y permite aquilatar su racionalidad".

\section{HABLAR CON CLARIDAD}

Estrechamente vinculada con la transparencia, aparece esta categoría nítidamente delineada en la jurisprudencia del TCA. Allí donde hay un actuar poco transparente -que como tal omite revelar informaciones, datos o documentos que pueden ser relevantes a las actuaciones y/o a los intereses de la contraparte-, hay también un hablar con poca claridad: las expresiones son muy próximas y el concepto es el mismo pues, según se viera, la transparencia se define a partir de la claridad. Con el agregado de que la categoría que nos convoca se refiere a una vertiente particular de la falta de transparencia y de claridad: la poca claridad en el hablar, en la expresión. Los sujetos deben expresarse con claridad, so pena de soportar las consecuencias de su falta de claridad ${ }^{27}$.

La obligación de hablar con claridad es el corolario natural de una serie de figuras jurídicas y de valores que planean la buena fe: la escrupulosidad, la autorresponsabilidad y la confianza. El primero de estos valores, la escrupulosidad, tampoco escapa a la falta de concreción que es propia del principio general: las nociones están ahí, pero es difícil traducirlas en una definición que vaya más allá de la mera permuta de palabras y se traduzca en un verdadero aporte, en una delimitación del concepto. Todos asociamos la escrupulosidad con una carga, un plus, un esfuerzo adicional de detallismo, minuciosidad y prolijidad.

En segundo lugar, convocamos la denominada autorresponsabilidad, es decir, la obligación de toda persona de hacerse cargo y responder por sus propios actos, recogida en el antiguo aforismo confor-

24 Amelia González Méndez da un paso más y dice que se conecta con la buena fe no solo la motivación del acto administrativo, sino toda información proporcionada por la Administración, en la medida en que, "al hacer explícita la razón de la decisión adoptada, permite la reacción del sujeto afectado en la defensa de sus intereses y derechos, amén de facilitar, en su caso, el acceso a la jurisdicción" (2001, p. 184). También sugerimos revisar lo desarrollado por Rubinstein, F. (2009, p. 184); Rodrigues, M. S. (2007, p. 66); Rodrigues, I. T. (2003, p. 38).

25 Esa circunstancia creemos que nos exime de mayores desarrollos y es la razón por la cual en esta parte hemos procurado limitar nuestro estudio a las líneas jurisprudenciales que entendimos más salientes.

26 En este sentido, véase la Sentencia 287/2015 del Tribunal de lo Contencioso Administrativo de Uruguay.

27 Gamarra Sagarra habla de claridad informativa, a la que ubica en el marco de la obligación de colaboración (2011, pp. 21-22). 
me el cual nadie puede ampararse en su propia culpa. Por fin, en la antesala de la obligación de hablar con claridad está la confianza, que es una de las notas definitorias de la buena fe, al decir de Gamarra Sagarra (1977, p. 271). Parafraseando a dicho civilista, el principio de la confianza significa que quien emite una declaración (en nuestro caso: en el marco de una relación jurídico-tributaria) o actúa un comportamiento (en ese mismo marco), suscita en el destinatario, la confianza de que el acto es serio y conforme a su significado objetivo (Gamarra Sagarra, 2011, p. 58). Sobremanera cuando la declaración emana de una autoridad pública, cuya actuación debemos asumir veraz.

La obligación de hablar con claridad se traduce en el deber de expresarse de manera precisa, libre de ambigüedades y, al mismo tiempo, con el nivel de información suficiente como para permitir la cabal comprensión del mensaje o declaración que se desea transmitir. Quien transgrede ese deber de claridad, deberá soportar las consecuencias de su propia oscuridad de expresión.

Inspirado en estas pautas, los reportorios de la jurisprudencia tributaria recogen fallos en los cuales se descarta de plano la demanda por falta de claridad en el planteo: no se había articulado con claridad el agravio del contribuyente. En otros, se anula la determinación por la falta de claridad a la hora de explicitar los periodos fiscales a los cuales correspondía el adeudo tributario, en términos tales que impedían al contribuyente una defensa cabal.

\section{LA PROSCRIPCIÓN DEL ARDID}

No es casualidad que la proscripción del ardid sea estudiada -lo mismo que la obligación de hablar con claridad-inmediatamente después de habernos detenido en la transparencia impuesta por la buena fe. La falta de transparencia y la proscripción del ardid guardan estrecho parentesco: en ambas hay un proceder que no es cristalino, que no es diáfano, que por alguna razón -reñida con la ley (ya con su letra, ya con su espíritu) - oculta alguna circunstancia. Así, cuando el acto administrativo carece de motivación, caracteriza una hipótesis de falta de transparencia.
La misma falta de transparencia se observa cuando una Administración pública, contraviniendo lo que es de estilo, deliberadamente omite dar intervención a una de sus reparticiones u organismos dictaminantes. En ambos casos hay un proceder omiso. Pero en la segunda hipótesis las circunstancias del caso -tan decisivas en este terreno ${ }^{28}$ caracterizan un plus que denota un ánimo, un fin reprobable: una reticencia maliciosa susceptible de inducir en error o de ambientar una creencia errónea, siempre en aras de obtener un resultado contrario a derecho ${ }^{29}$.

La reciente jurisprudencia tributaria del TCA es conteste en la reprobación de aquellas conductas que importan una estratagema, una maquinación, un proceder artero, espurio, en aras de procurar un resultado reprochable. Un resultado que, de no mediar el engaño artificioso (para usar la feliz expresión del artículo 347 del Código Penal Uruguayo), no sería posible. Son conductas que apuntan a eludir la letra o el espíritu de la ley, y por eso son condenables. Esa reprobación se ha traducido invariablemente en la privación de efectos al acto en cuestión.

Quizás el ejemplo más claro sea la denominación con el título de acta final de inspección a un documento que en verdad no cumple con las características de tal ${ }^{30}$. Vale decir: no habiendo concluido el procedimiento inspectivo, la Administración expide un documento al que denomina acta final de inspección, que en rigor no es tal. ¿Para qué? Para alcanzar el efecto interruptivo de la prescripción que el artículo 39 del Código Tributario Uruguayo atribuye a la denominada acta final de inspección.

Al igual que las restantes figuras que aquí se estudian, también esta podría encararse bajo la óptica del rechazo del formalismo excesivo (que veremos en breve), en cuanto el temperamento del Tribunal con todo acierto privilegia el fondo sobre la forma. Sin embargo, hemos optado por la inclusión en este rubro porque creemos que es la motivación elusiva, el obrar malicioso, el eludir la finalidad de la ley-en el caso, sortear el escollo legal: la inminente prescripción del crédito fiscal- el que colorea la figura. Vale decir que allí donde el acto emanado de la Administración no es sustancial y ontológicamente un

28 Norberto Spolansky, a propósito de las circunstancias que enmarcan la estafa, ha escrito: "No existen [...] mentiras ardidosas en sí, sino en relación a quien se presenten" (1969, p. 71).

29 A mayor ahondamiento, véase Bayardo Bengoa, F. se extendía a propósito de los medios infinitos y de las múltiples formas para llegar al engaño (1961, p. 142 y ss.).

30 El verdadero sentido del instituto ha sido despejado por José Gómez Leiza, con el rigor que le caracteriza. Sobre el particular, véase Gómez Leiza, J. (2013, pp. 386-395). A través del artículo 6 de la Ley 18.788 se ha establecido el contenido que necesariamente deben presentar las actas finales de inspección de la Dirección General Impositiva de Uruguay. 
acta final de inspección, el TCA uruguayo ha descartado el efecto interruptivo de la prescripción que por el Código Tributario Uruguayo corresponde al acta final de inspección ${ }^{31}$.

También es apropiado convocar en este capítulo aquellas situaciones en las cuales se aprecia una alteración inesperada en el iter procedimental normal. Así, en algún caso fallado en Uruguay, resultó que luego de conferida la vista y antes de que venciera el plazo de 15 días del que disponía el contribuyente a efectos de evacuarla, la Administración dio marcha atrás y ordenó pasar directamente al dictado del acto de determinación, sin aguardar que los interesados hicieran las defensas a las que tenían legítimo derecho.

¿Por qué lo hizo? Porque de la reliquidación practicada había surgido un adeudo cuantitativamente inferior para la empresa. Por dicho motivo, mientras los interesados estaban aún en plazo para articular sus descargos, y sin haber sido oídos, se ordenó pasar al acto de determinación. Finalmente, el TCA anuló el acto, invocando precisamente el principio de la buena fe, la coherencia en el comportamiento, y la seguridad jurídica ${ }^{32}$.

Por otro lado, en otro asunto fallado por la jurisprudencia uruguaya, la Administración tributaria no dio participación a sus cuadros legales internos para evitar que estos relevaran precisamente el derecho que el contribuyente quería hacer valer ( $y$ que la Administración le denegaba): su derecho a presentar reliquidaciones.

Hay aquí un proceder avieso, torcido: se desvía o se altera el curso natural del procedimiento, siempre con un móvil artero, a saber, el abatimiento en el importe reliquidado o procurar que no salgan a relucir posibles debilidades en la postura jurídica de la Administración. En cualquiera de ambos casos el proceder de la Administración -el artilugiono es presidido por la recta aplicación de la ley, sino por el objetivo de prevalecer en el juicio. Y esa actuación es contraria a la buena fe.

En suma, la proscripción del ardid, vinculada estrechamente con la transparencia, excluye y reprueba las conductas que van más allá de los márgenes de lo permisivo en la natural puja por prevalecer en el procedimiento o en el proceso. Y es en la motivación subyacente de esas conductas donde el intérprete habrá de discernir el umbral de la licitud, una vez atravesado el cual el comportamiento se tendrá por violatorio de la buena fe.

\section{COHERENCIA}

Se trata de una cualidad inherente al orden jurídico, que se presume coherente, es decir, sistemático y exento de contradicciones ${ }^{33}$. Allí, donde se detecta una contradicción, el intérprete procura superarla y conciliar los textos o las lecturas que se presentan contradictorias.

Coherencia significa uniformidad de criterios, de argumentación y de actuación ${ }^{34}$. En la medida en que hay uniformidad, puede existir previsibilidad, la cual, a nuestro juicio, debiera ser una aspiración de todo orden jurídico. La previsibilidad es la consecuencia natural de esa uniformidad: un comportamiento imprevisible se aparta del padrón de uniformidad y deviene incoherente.

Esa coherencia es propia de la buena $\mathrm{fe}^{35}$. Si aceptamos que la buena fe es, entre otros, un modelo

31 El lector atento advertirá que a la postre no se trata más que de una aplicación concreta del renombrado inciso segundo del artículo 6 del Código Tributario:

Las formas jurídicas utilizadas por los particulares no obligan al intérprete; éste deberá atribuir a las situaciones y actos ocurridos una significación acorde con los hechos, siempre que del análisis de la norma surja que el hecho generador fue definido atendiendo a la realidad y no a la forma jurídica (Decreto Ley 14306, 1974).

Hay sin embargo un escollo: la norma refiere únicamente a las formas jurídicas utilizadas por los particulares, omitiendo toda referencia a las que la Administración pudiere adoptar. La respuesta a esa asimetría ha sido aportada por Mario Ferrari Rey: el Código Tributario Uruguayo fue redactado bajo la premisa de que la Administración actúa de buena fe (2016, pp. 233 y ss.).

32 En este sentido, véase la Sentencia 391/2014 del Tribunal de lo Contencioso Administrativo de Uruguay.

33 Quintín Alfonsín escribía que "es jurídicamente imposible que dos normas contradictorias sean válidas a la vez (y si bien en los hechos ello puede suceder) nos ponemos a buscar una solución para restablecer la unidad de validez violada" (2016, p. 3).

Hay, sin embargo, discrepancias en torno a este punto de partida. Al respecto, véase Blanco Beltrán, A. (2011, p. 97). También Serrana Delgado Manteiga ha señalado algún matiz (2017, p. 33).

34 Luis Díez-Picazo ha escrito que "a la Administración le es jurídicamente exigible cierta coherencia en sus actuaciones. Un comportamiento injustificadamente desigual, es incompatible con esa coherencia y constituye por el contrario una arbitrariedad [...]". Y agrega más adelante que "[esa] coherencia administrativa, compuesta fundamentalmente de objetividad y criterios uniformes, es indispensable para cumplir lo que puede llamarse principio de buena administración" (1982, p. 49).

35 En esa misma línea se expresa Pedro J.J. Coviello, siguiendo a Diez-Picazo (2004, p. 404). También en Argentina, la Corte Suprema de la Nación ha establecido que una de las derivaciones de la buena fe es precisamente el derecho de todo ciudadano "al comportamiento leal y coherente de los otros, sean estos los particulares o el propio Estado" (Fallo 312: 1725, 1989). 
de conducta que se traduce en derechos y obligaciones o prestaciones y especialmente en expectativas, las cuales solo pueden ambientarse en un marco de coherencia. La relación entre la coherencia y la buena fe es tan íntima que algunos autores encuentran en la buena fe el fundamento (o a menos uno de ellos) del carácter vinculante de precedente administrativo ${ }^{36}$. Allí donde el comportamiento es incoherente, no es factible esperar del individuo comportamiento alguno, precisamente porque falta la mentada uniformidad.

En el tráfico jurídico se da por sentado que cualquier sujeto que entra en relación con otro u otros, espera de este o de estos, un comportamiento coherente. Con coherente nos referimos a libre de contradicciones, en términos tales que una determinada conducta no haya de resultar incompatible con otra (del mismo sujeto) previa o concomitante. Esto, naturalmente, aplica al propio Estado pues la persecución de un fin púbico no le exime de esta clase de ataduras o condicionamientos. El Estado es también custodio de la buena fe en las relaciones jurídicas y como tal, no puede ni debe sorprender a los particulares con cambios de actitud, con comportamientos bruscos o intempestivos que colidan con otros emanados del mismo cuerpo y que no serían tolerados en el Derecho privado ${ }^{37}$.

Bajo esta perspectiva, la jurisprudencia tributaria ha entendido que allí donde la Administración consideró configurada una unidad económico-administrativa, correspondía a esta realizar un balance consolidado y en su mérito practicar una única liquidación. En igual sentido, el Tribunal ha establecido que cuando la Administración ha concluido que el director actuante era un testaferro, no es posible responsabilizar al mismo tiempo y por la misma conducta, a quien se releva como el verdadero director y representante, y a su testaferro. Por fin, el TCA ha subrayado la incoherencia del contribuyente que se valió de un régimen legal y reglamentario de excepción para la regularización de obligaciones tributarias sin multas y recargos, sin querer asumir la contrapartida de esa remisión del Estado que es la actualización de las obligaciones debidas por los índices dominantes.

\section{EL DEBER DE DECIR LA VERDAD}

El deber de decir la verdad es tan esencial al Estado de Derecho como lo es la buena $\mathrm{fe}^{38}$. No se concibe la buena fe $-\mathrm{y}$ damos un paso más: ni el orden jurídico en su conjunto- si ella no va acompañada del deber de decir la verdad y de la proscripción de la mentira. Quien dice la verdad, actúa de buena fe; quien miente, falta a la verdad y, por lo mismo, transgrede el principio de buena fe. $\mathrm{Si}$ el sentido de la buena fe, o al menos uno de ellos, es alcanzar la solución justa en el caso concreto, no es posible llegar a la solución justa si no es a través de la verdad ${ }^{39}$. En esa misma línea, en Argentina se ha escrito que "a la verdad no se accede sino mediante la buena fe" (Bidart Campos, 2004, p. 48$)^{40}$. De manera tal que un procedimiento administrativo dominado por la falta de la verdad -sea de la Administración, sea del contribuyentea nuestro juicio, es un procedimiento viciado y como tal compromete la validez del acto administrativo que representa su culminación.

Este imperativo ético no ha escapado a la jurisprudencia que nos convoca. Más de una vez el Tribunal ha reprochado a los involucrados haber faltado a la verdad. A veces en cuanto al relato de los hechos y a veces, incluso respecto del propio derecho. Todo individuo tiene el deber de decir la verdad, aun el propio incriminado. $Y$ al mismo tiempo tiene también el derecho a articular su defensa -incluido el derecho a muñirse del asesoramiento profesional correspondiente- $y$, en particular, a no declarar en contra de sí mismo.

36 Confróntese, Díez-Picazo, L. (1982, p. 9). El prestigiado autor español ha podido escribir que "el principio de la buena fe se basa en la legítima expectativa de que deben producirse en cada caso consecuencias usuales, las que se han producido en casos similares. Esa legítima expectativa se defrauda cuando la Administración, sin motivo, se aparta de sus precedentes". Y agrega: "esa coherencia administrativa, compuesta fundamentalmente de objetividad y criterios uniformes, es indispensable para cumplir lo que puede llamarse principio de buena administración” (1982, pp. 14-15).

38 Ya en su fermental estudio del año 1958, Barbe Pérez identificaba el deber de decir la verdad como un principio general que subyace todo el ordenamiento (p. 47).

39 Con su proverbial claridad, Couture escribía:

Es posible afirmar que existe un principio ínsito (aunque no exista texto expreso) en el Derecho Procesal, que determina un deber de las partes de decir la verdad [...]. El proceso tiene cierta nota de necesaria, cierta inherencia de verdad, porque el proceso es la realización de la justicia, y ninguna justicia se puede apoyar en la mentira (2003, p. 167). Confróntese, Véscovi, E. (1958, pp. 174 y ss.). A partir del Código General del Proceso, el texto a que Couture aludía, hoy es una realidad plasmada en nuestro Derecho positivo: es el artículo 63 (inciso segundo) de aquel, que establece que los actos procesales "habrán de ser realizados con veracidad y buena fe [...]" (Véscovi, 1992, pp. 130-134; 1993, pp. 282-283).

40 Confróntese, Palacio, L. E. (2004, p. 819). 
Aun cuando en la práctica pudiera vislumbrarse una cierta tensión entre ambas figuras, lo cierto es que el deber de decir la verdad se traduce -a nuestro juicio- en la proscripción de la mentira: a nadie le es lícito mentir, ni aun en causa propia. Sin embargo, ese deber de decir la verdad no significa en modo alguno que el sujeto deba autoincriminarse ni que esté obligado a declarar en su contra; precisamente porque el derecho mencionado se erige en una valla en la cual el inspeccionado puede ampararse.

El conflicto entre ambos institutos es menos frontal de lo que una primera mirada pudiera sugerir. El derecho a no incriminarse no significa que el individuo esté legitimado a faltar a la verdad o que exista en esos casos un derecho a mentir: significa sí que el sujeto puede no responder determinadas preguntas, o abstenerse de determinadas aseveraciones, si cree que las mismas pudieren incriminarle. En suma, que tiene derecho a guardar silencio ${ }^{41}$.

Recordamos también que, fundamentalmente, el deber de decir la verdad no implica la obligación de decir toda la verdad; implica sí la exclusión de la mentira. He aquí, a nuestro juicio, los márgenes legales dentro de los cuales puede y debe navegar una defensa plenamente conciliable con el deber de decir la verdad, sin mengua del derecho a no declarar en contra de uno mismo.

\section{EL RECHAZO DEL FORMALISMO EXCESIVO}

¿A qué llamamos formalismo excesivo? El concepto es particularmente amplio y guarda relación con diversas nociones que ya son familiares al lector. Aquel se vincula con la incidencia de los vicios formales (intrascendentes) en el procedimiento y/o en el acto administrativo, entendiéndose por tales aquellos que tienen que ver con las formalidades o con la forma del acto administrativo ${ }^{42}$.

Otro tanto cabe decir de la prevalencia del fondo sobre la forma. Allí donde el espíritu o la intención de la norma han sido satisfechos, corresponde te- ner la norma o la exigencia cumplida, aun cuando las formalidades no se hayan visto colmadas en toda su dimensión.

Por fin, guarda también puntos de contacto con el rechazo del llamado legalismo de la interpretación, conforme al cual el Derecho debe fundarse exclusivamente en la ley escrita y en la interpretación meramente declarativa o reproductiva de un significado preexistente. Vale decir, el legalismo prescinde de la consideración de toda clase de elementos extrínsecos, ajenos a la ley y, muy especialmente, de las circunstancias del caso $^{43}$. Es un lugar común la cita de Cicerón (44): el formalismo extremado puede llevar a la injusticia extrema (summum ius, summa injuria $)^{44}$.

Pero al mismo tiempo, el rechazo del formalismo excesivo es todo eso y también algo más: es la prevalencia de lo relevante sobre lo accesorio, para usar la feliz expresión de Pezzutti ${ }^{45}$, es la interpretación que aplica la norma teniendo en cuenta la realidad vital (Gamarra Sagarra, 2014b, p. 134). Es la visión del bosque que se impone sobre la del árbol aisladamente considerado, es la interpretación que privilegia el interés que el Derecho procura proteger (Alferillo, 2004, p. 249), que prioriza la finalidad y el espíritu de la norma, frente a la letra de esta abstraída de sus circunstancias; la interpretación que en esa necesaria y fluida interacción entre la norma y el caso concreto, jerarquiza el rol de las circunstancias que influyen en la interpretación (Gamarra Sagarra, 2014b, p. 94). En síntesis, es la buena fe en la interpretación y aplicación de la norma, si se nos permite la tautología (Gastaldi, 2004, p. 131).

Estas consideraciones no resultan fortuitas, porque la buena fe aparece indisolublemente vinculada a las circunstancias del caso, que el formalismo excesivo relega para centrarse puramente en los elementos textuales. Si la buena fe pretende ser expresión de lo justo, ese sentido de justicia emerge del análisis del caso, de los hechos. Por eso, con total propiedad se ha dicho que la buena fe importa el rescate y la jerarquización de las

41 Véase, Zarini, H. J. (2016).

42 Hace 60 años, Héctor Giorgi escribía en su tesis:

El vicio de forma consiste en la omisión del cumplimiento de los procedimientos y formas que el Derecho impone a la Administración para la formulación del acto [...]. Al referirnos al vicio de forma, comprendemos no sólo la forma del acto, sino también los requisitos de procedimiento a que está sometida la Administración en su actuación (1958, p. 201).

Asimismo, justo es rendir tributo a la integración del ilustre Tribunal que evaluara la conocida monografía del aspirante: Enrique Sayagués Laso, Alberto Ramón Real, y Héctor Barbé Pérez.

43 El pensamiento pertenece a Gamarra Sagarra (2014a, p. 14). Más ampliamente, véase del mismo autor (2014b, pp. 91- 110).

44 La frase completa es algo más extensa: Existunt etiam saepe iniuriae calumnia quadam et nimis callida sed malitiosa iuris interpretatione. Ex quo illud summum ius summa iniuria factum est iam tritum sermone proverbium (Cicerón, 44, 33).

45 Como consta en el prólogo de Presno Arturo, M. y M. Ramos Palermo (2016, p. 16). 
circunstancias del caso a la hora de procurar la dilucidación de este.

Quizás una de las expresiones jurisprudenciales más salientes a este respecto tiene que ver con las formalidades documentales que deben observarse a efectos de que un gasto sea deducible para llegar a la materia imponible en sede de impuesto a la renta corporativo. La jurisprudencia tributaria uruguaya ha aceptado que cuando la existencia del gasto y su cuantía no resultan controvertidas, no corresponde objetar la deducibilidad del gasto en función de las eventuales carencias formales que la documentación pudiera exhibir. En el mismo sentido, y contrariando posturas inveteradas de la Administración, la jurisprudencia uruguaya ha insistido en que la responsabilidad del director debe cesar allí cuando su efectiva injerencia en la materia tributaria haya concluido, más allá de si se haya cumplido o no con la formalidad de comunicar su desvinculación a la Administración (presentando el correspondiente formulario de baja).

\section{EL COMPORTAMIENTO SOLIDARIO}

He aquí otro de los valores que inspiran el principio de la buena fe y que se trasunta en varias de las exigencias arriba reseñadas. La solidaridad -establecida a texto expreso por la Constitución italiana como deber general ${ }^{46}$ - es la consideración de los intereses de la otra parte ${ }^{47}$. Esta refiere a una serie de deberes de colaboración que, de no cumplirse, afectan desfavorablemente los intereses de la otra parte -en la medida determinada en cada caso- al propio ejercicio del derecho o a los términos del cumplimiento de la obligación (González Méndez, 2001, p. 170).

En esa misma línea, en España, el artículo 34 de la Ley General Tributaria, en consonancia con la antigua Ley de Derechos y Garantías de los Contribuyentes, alude no solamente a deberes de colaboración, sino también a la no obstaculización del ejercicio de los derechos del contribuyente o del cumplimiento de la obligación tributaria, y al desarrollo de las actuaciones de la Administración tributaria (que requieran la intervención de los contribuyentes) de la manera menos gravosa para estos (Ley 58/2003). En Uruguay, Gamarra Sagarra señala que la obligación de colaborar deriva de la esencia misma de la solidaridad y la que mejor la expresa (2011, p. 47). En cierta medida, algunos de los derechos (y correlativos deberes) estatuidos en el Código Tributario uruguayo, son expresión de ese deber de colaboración que podríamos dar en llamar solidaridad tributaria.

Ese rechazo del comportamiento mezquino, ha aflorado una y otra en la jurisprudencia del TCA, siempre con un semblante que hace a la singularidad del caso: cada especie encierra su propia riqueza, de manera que no hay dos procedimientos administrativos exactamente iguales. Siempre teniendo presente, como se puntualizaba al comienzo, que las categorías rara vez son excluyentes y también que rara vez se presentan en estado de pureza.

La reflexión es pertinente porque la duración razonable que se comentará en el apartado siguiente -las partes deben actuar con una diligencia tal que el procedimiento no se dilate más allá de lo estrictamente necesario- es expresión también del deber de colaboración impuesto por la solidaridad. Ingresan bajo este capítulo los fallos en que el Tribunal reprueba la no devolución de documentos en poder de la Administración, su incumplimiento a la obligación de mitigar el daño del contribuyente, o bien, por fin, la falta de cooperación del contribuyente en el procedimiento inspectivo.

\section{LA PRO-ACTIVIDAD DE LA ADMINISTRA- CIÓN: LA DURACIÓN RAZONABLE DEL PRO- CEDIMIENTO $^{48}$}

La proactividad y el comportamiento activo de cooperación, es una de las tantas manifestaciones de la buena fe (y en particular de uno de los valores que le subyacen: la solidaridad). Esa solidaridad se pone sobremanera de relieve en el marco de relaciones de larga duración, como suele ser la relación entre la Administración tributaria y el contribuyente ${ }^{49}$. Es en el contexto de estas relaciones en que los deberes de colaboración impuestos por la buena fe irrumpen en toda su dimensión (Gamarra Sagarra, 2011, pp. 17-19).

Es pertinente estudiar la duración del procedimiento en el marco del principio de la buena $\mathrm{fe}^{50}$ :

46 Sobre este punto, el artículo 2 de la Constitución italiana alude a "deberes de solidaridad política, económica y social”.

47 En la literatura civil, Juan Benítez Caorsi la resume en los términos que siguen: "cooperación leal y honesta de las partes en vista de la realización de los beneficios recíprocos acordados por el contrato". Y agrega: "hacerse cargo del interés del otro no se limita solamente a preservar su existencia, sino a garantizar razonablemente su realización" (2013, p. 21).

48 Este apartado recoge un análisis del autor publicado en la RT 253, pp. 501 y ss.

49 Véanse González Méndez, A. (2001, pp. 176-177); Rodrigues, I. T. (2003, p. 37).

50 Naturalmente ello no obsta a que la duración del procedimiento pueda estudiarse también a la luz de otros principios, especialmente el de la seguridad jurídica. En nuestro medio, así lo hizo Labaure Aliseris, C. (2011, p. 87 y ss.) y años más tarde Agostino Giraldez, S. (2014, pp. 783-784). 
no es la larga duración del procedimiento la que violenta la buena fe, sino la indolencia o desidia que hay detrás de esos procedimientos que se perpetúan en el tiempo ${ }^{51}$. En ausencia de esa abulia administrativa, no hay -al menos del lado de la Administración- transgresión alguna de la buena fe, por extendida que pudiera ser la duración del procedimiento. El paréntesis es pertinente, porque muchas veces es el contribuyente o responsable quien, transgrediendo el imperativo de la buena fe, asume comportamientos dirigidos a obstaculizar, entorpecer o prolongar innecesariamente los procedimientos administrativos a través de dilaciones injustificadas (Rodrigues, 2003, p. 38).

Sin desconocer que la proactividad impuesta por la buena fe se proyecta de múltiples maneras -algunas de ellas reseñadas en el apartado anterior-, en esta sección nos ocuparemos de una de las más significativas: la duración del procedimiento tributario. Esta se refiere a la imperiosa necesidad de que sus tiempos sean los estrictamente necesarios ${ }^{52}$.

En materia tributaria, la duración del procedimiento ofrece alguna singularidad: en tanto el procedimiento tributario transcurre, la no extinción de la deuda por tributos en el plazo correspondiente significa que los recargos por mora se continúan devengando día a día. A lo cual cabe añadir los embargos que suelen subsistir durante el transcurso del procedimiento.

Quiere decir que, sobremanera en esta materia, el transcurso del tiempo no es indiferente al derecho (Sentencia 507/2014, 2014). Por un lado, por las razones apuntadas y, por otro, por la carga emocional, la intranquilidad familiar y el estado de incertidumbre que supone el decurso de una inspección tributaria, o más ampliamente, de un procedimiento tributario ${ }^{53}$ (Delpiazzo, 2011b, p. 75).

En Uruguay no existe una previsión legal expresa (o aun reglamentaria) que establezca un plazo definido o determinado para la duración del procedimiento tributario. Existen, en cambio, principios generales de celeridad, eficacia y buena administración que inspiran todo procedimiento administrativo, tal como lo preconiza el artículo 2 del Decreto 500. Este agrega, en su artículo quinto: "Los interesados en el procedimiento administrativo gozarán de todos los derechos y garantías inherentes al debido proceso [...]. Estos derechos implican un procedimiento de duración razonable [...]" (1991). Términos similares son referidos en el artículo 8 del Pacto de San José de Costa Rica, de expresa aplicación en materia fiscal: "Toda persona tiene derecho a ser oída, con las debidas garantías y dentro de un plazo razonable [...]" (1969).

A partir de esas premisas, el TCA tiene establecido (al menos de manera implícita) que la duración de la inspección no puede involucrar "una demora excesiva, irracional e injustificada" (Sentencia 256/2013, 2013): el procedimiento tributario debe tener un plazo razonable que, como tal, no puede dilatarse indefinidamente.

Resta despejar qué significa -en la jurisprudencia del TCA- un plazo de duración razonable: ¿cuándo el plazo de una inspección puede o debe entenderse razonable? La jurisprudencia dominante del TCA reconoce el principio de duración razonable del procedimiento (lo mismo que los principios de administración eficiente y seguridad jurídica), y acepta también que es posible reclamar su cumplimiento por parte de la Administración. Sin embargo, afirma que ese principio coexiste con otros, como los principios de verdad material y debido proceso.

En ese sentido, dicho tribunal ha expresado lo siguiente:

[...] los principios, a diferencia de las reglas, no se aplican en términos de todo o nada, sino de acuerdo a su dimensión de peso en la argumentación [...] es el juicio de ponderación

51 En España, Amelia González Méndez ha escrito -en punto al plazo de duración de los procedimientos administrativosque su cómputo no puede verse interrumpido o paralizado por dilaciones imputables a la Administración. Y agrega: "la remoción de tales situaciones no se justifica en base al principio de seguridad jurídica in genere, sino en razón a la existencia de un comportamiento contrario a la buena fe y a la lealtad que debe a la otra parte de la relación jurídica" (2001, p. 176).

52 Lo mismo podría decirse -ya en sede de la Justicia civil-a propósito de la vigencia de las medidas cautelares por aquella decretadas: ¿durante cuánto tiempo debieran ellas regir? Durante el tiempo estrictamente necesario para cumplir su función. En el caso de Geralin S.A y Giordano e Hijos Sociedad de Bolsa contra la Dirección General Impositiva, el Tribunal de apelaciones civil de segundo turno denegó el pedido de la Administración de prorrogar las medidas cautelares vigentes, por entender que la demora considerable en la tramitación del expediente administrativo "resulta imputable en forma exclusiva a la Administración [...] el Tribunal encuentra como excesivos determinados plazos y tiempos que no encuentran a priori justificación razonable". Y concluye: "lo que no puede avalarse es la continuación de un proceso cautelar por más de siete años, que no tiene a la fecha un fin próximo" (2016).

53 Justo es decir que muchas veces la dilación obedece a actitudes dilatorias y reticentes de los particulares. En numerosas ocasiones es el investigado el primer interesado en dilatar el procedimiento, o bien, adopta una actitud pasiva o reticente que conspira contra el avance fluido de aquel. Aquí nos ocupamos únicamente de aquella duración irrazonable del procedimiento cuyo exceso es atribuible exclusiva o principalmente a la Administración. 
que llevará a decidir cuáles principios se priorizando -dada una determinada hipótesis de hecho-y cuáles se dejan en un segundo plano [...] La Sala estima que el conflicto entre los principios que rigen el procedimiento administrativo debe resolverse caso a caso, considerando las circunstancias que particularizan la situación (Sentencia 256/2013, 2013).

Vale decir que la jurisprudencia del TCA pone énfasis en la ponderación de principios, el necesario balance y contrapeso entre los principios en juego: por un lado, los de duración razonable y celeridad, y los principios del debido proceso y de búsqueda de la verdad por el otro. Estos, en opinión del tribunal, en cierta medida son "de signo contrario" o "entran en contradicción" 54 (Sentencia 831/2012, 2012).

Nosotros compartimos la incidencia de los diversos principios, aunque con algún matiz: no creemos que en esta materia esos principios entren en colisión, sino que, desde nuestro punto de vista, unos y otros se potencian recíprocamente y se integran sin esfuerzo. Cuando decimos que la duración del procedimiento ha sido excesiva, hacemos alusión a un procedimiento en el cual, cumplidas las exigencias del caso -sobre todo las conexas con el derecho a una defensa razonable y las vinculadas al deber de la Administración de llegar a la verdad-, y transcurridos los tiempos razonablemente necesarios para atender el conjunto de esas exigencias (y aun aquellos que pudieren haber suspendido el avance de las actuaciones por justas causas), el procedimiento no fue concluido, sin razón valedera alguna. Es decir, el exceso comienza luego de encontrarse satisfechas las necesarias garantías que deben rodear todo procedimiento. Hasta ahí, no hay exceso ni irrazonabilidad algunos.

Posteriormente, hay un punto de inflexión: un momento hasta el cual la duración se considera razonable. A partir de ese mismo momento, todo el tiempo que transcurra -sin que se dicte y notifique el acto de determinación- será completamente innecesario, y, por ende, dará la medida del exceso. Es por eso que, a nuestro juicio, no hay en este caso conflicto de principios: antes bien, la tutela jurisdiccional y la necesidad de llegar a la verdad, son precisamente los que nos van a dar la medida de la irrazonabilidad de la duración, los que nos han de indicar el lapso necesario para su satisfacción y, por ende, los que han de marcar el hito o umbral a partir del cual la duración del procedimiento será considerada desmedida o carente de sentido ${ }^{55}$.

Porque el particular no reclama un pago, sino que aspira a privar de efectos la pretensión del cobro de aquellos recargos que, de no haber mediado una omisión culpable de la Administración, no se habrían generado. El resultado económico puede ser el mismo, pero la pretensión jurídica y la mecánica procesal son completamente diferentes: aquí nadie pide al Estado una sentencia de condena (al resarcimiento de un daño), sino la anulación parcial del acto administrativo, exclusivamente en aquella parte que determina la obligación de pagar una suma de dinero por concepto de recargos.

Creemos que este planteamiento armoniza con los principios de administración eficiente y, fundamentalmente, con el sentido común y la razonabilidad que planea todo orden jurídico: no parecería razonable que el agraviado deba aguardar a las resultas de un juicio reparatorio patrimonial para ver resarcido el daño sufrido. Y menos lógica aún pareciera la pretensión de hacer valer $-y$, sobre todo, ejecutar- un acto administrativo a sabiendas de que su licitud va a ser cuestionada de inmediato

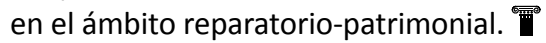

\section{REFERENCIAS}

Alferillo, P.E. (2004). Reflexiones sobre la vinculación de la mala fe con los factores de atribución subjetivos. En Córdoba, M. M. (coord.) Tratado de la buena fe en el Derecho (1ra ed., pp. 219252). Buenos Aires: La Ley.

Alfonsín, Q. (2016). Introducción a la teoría general del Derecho Internacional Privado. La Justicia Uruguaya, (154), pp. 179-189.

Agostino Giraldez, S. (2014). El principio de la seguridad jurídica en el Derecho Tributario. Revista Tributaria, (242), pp. 766-792.

54 Aunque seguramente implícito, creemos que al primer grupo de principios debiera agregarse el de la buena fe, en cuanto impone a la Administración la obligación de asumir un comportamiento proactivo en la búsqueda de la verdad. Es pertinente traer a colación, también, los principios de contradicción (como manifestación del derecho a defenderse en vía administrativa recogido en el inciso j del artículo 2 del Decreto 500), y los principios de eficacia y eficiencia administrativa. A mayor ahondamiento, véase Cajarville Peluffo, J. P. (2007, pp. 221-ss).

55 Como se comprenderá, la fijación de ese momento en el tiempo dista de ser un mecanismo perfecto y exacto. Aun así, se trata de establecer -con criterios de razonabilidad- una línea de corte, sea el momento en que la recolección de la prueba fue agotada, sea el momento en que se comenzaron a instruir actuaciones superfluas, sea el momento en el cual, sin razones aparentes, el expediente dejó de avanzar. Una vez más, la equilibrada ponderación del juez en el caso concreto es la que tendrá la última palabra. 
Bayardo Bengoa, F. (1961). Derecho Penal Uruguayo (tomo 9, 1ra ed.).

Barbe Pérez, H. (1958). Los principios generales de derecho como fuente de derecho administrativo en el derecho positivo uruguayo. En Universidad de la República, Estudios Jurídicos en Memoria de Juan José Amézaga (pp. 35-55). Montevideo: Universidad de la República.

Blanco Beltrán, A. (2011). Categorización de responsables tributarios: Fundamentación de soluciones y contradicciones normativas. Revista Tributaria, (220), pp. 77-98.

Benítez Caorsi, J. (2013). Solidaridad contractual: Noción posmoderna del contrato. Madrid: Reus Editorial.

Bidart Campos, G.J. (2004). Una mirada constitucional al principio de la buena fe. En Córdoba, M. M. (coord.) Tratado de la buena fe en el Derecho (1ra ed., pp. 43-54). Buenos Aires: La Ley.

Cajarville Peluffo, J. P. (2007). Sobre Derecho Administrativo (tomo 2, 1ra ed.). Montevideo: Fundación de Cultura Universitaria.

Cassinelli Muñoz, H. (1962). El principio de la publicidad de la gestión administrativa (nota de jurisprudencia). Revista de Derecho, Jurisprudencia y Administración, 58 (7), pp. 162-163.

Cicerón, M.T. (44). De Officiis. Recuperado de thelatinlibrary.com/cicero/off1.shtml\#33

Couture, E.J. (2003). Estudios de Derecho Procesal Civil (Vol. 3, 3era ed.). Buenos Aires: Editorial Ediar.

Coviello, P. J. J. (2004). La Protección de la Confianza del Administrado. Buenos Aires: Lexis Nexis.

Delgado Manteiga, M.S. (2017). ¿Es posible que respondan tributariamente los representantes del responsable? Revista tributaria, (256), pp. 33-52.

Delpiazzo, C. (2003). De la publicidad a la transparencia en la gestión administrativa. Revista de Derecho (Universidad de Montevideo), (3), pp. 113-124.

(2005). Eficacia aplicativa de los principios generales de derecho en la contratación administrativa. Anuario de Derecho Administrativo, (13), pp. 65-77.

(2011a). Derecho Administrativo General (Vol. 1, 1ra ed.). Montevideo: Editorial y Librería Jurídica A.M.F. (2011b). Perspectiva positiva y tutelar de los plazos en el procedimiento administrativo. Revista de Derecho Público, (39), pp. 63-78.

Díez-Picazo, L. (1982). La doctrina del precedente administrativo. Revista de Administración Pública, (98), pp. 7-46.

Durán Martínez, A. (1999). La obligación de motivar: Un principio general de Derecho Administrativo. En Durán Martínez, A., Estudios de Derecho Administrativo- Parte General. Montevideo: s/e.

(2010). El Precedente Administrativo. Revista de Derecho, (5), pp. 51-78. https://doi. org/10.22235/rd.v0i5.816.

Ferrari Rey, M. (2016). La tutela jurisdiccional tributaria en Uruguay: ¿ilusión o derecho efectivo? La viabilidad de pequeños grandes cambios. Revista Tributaria, (251), pp. 233- 260.

Ferreira Rubio, D. (1984). La Buena Fe El Principio General en el Derecho Civil. Montecorvo: Madrid.

Gamarra Sagarra, J. (1977). Tratado de Derecho Civil Uruguayo (tomo 18, 1ra ed.). Montevideo: Fundación de Cultura Universitaria.

(1979). Tratado de Derecho Civil Uruguayo (tomo 13, 3ra ed.). Montevideo: Fundación de Cultura Universitaria.

(2006). Tratado de derecho civil uruguayo (tomo 9, 4ta ed.). Montevideo: Fundación de Cultura Universitaria.

(2009). Teoría del acto propio redimensionada. Análisis jurisprudencial. Anuario de Derecho Civil Uruguayo, (40), pp. 925-936.

(2011). Buena Fe Contractual. Montevideo: Fundación de Cultura Universitaria.

(2014a). Formalismo jurídico interpretativo a partir del estudio de una sentencia "ilegal". Tribuna del Abogado, (187), pp. 16-18.

(2014b). Las circunstancias del caso concreto en la interpretación y aplicación de la ley. Doctrina y Jurisprudencia de Derecho Civil, (2), pp. 91-110.

Gastaldi, J.M. (2004). La buena fe en el derecho de los contratos. En Córdoba, M. M. (coord.) Tratado de la buena fe en el Derecho (1ra ed., pp. 299-320). Buenos Aires: La Ley. 
Giorgi, H. (1958). El contencioso administrativo de anulación. Montevideo: Biblioteca de publicaciones oficiales de la Facultad de Derecho y Ciencias Sociales de la Universidad de la República.

Gómez Leiza, J. (2013). Análisis de las modificaciones al régimen de prescripción de las obligaciones tributarias por las leyes 18.788 y 18.834. Revista Tributaria, (234), pp. 386-395.

González Méndez, A. (2001). Buena fe y Derecho Tributario. Madrid: Marcial Pons, Ediciones Jurídicas y Sociales.

Labaure Aliseris, C. (2011). Seguridad jurídica y duración del procedimiento administrativo. En Pezzutti, M. (coord.), Seguridad jurídica y Derecho Administrativo. Montevideo: Fondo de Cultura Universitaria.

Larenz, K. (1985). Derecho justo. Fundamentos de ética jurídica (1ra ed.). Madrid: Editorial Civitas.

Lobo Torres, R. (2001). O princípio da transparência no direito financeiro. Revista de direito da associação dos procuradores do Novo Estado de Rio de Janeiro, (8), pp. 133-156.

López Rocca, E. (2003). Publicidad y secreto en la Administración Pública. Revista de Derecho Público, (24), pp. 39-88.

Mairal, H.A. (1988). La doctrina de los propios actos y la Administración Pública (1ra ed.). Buenos Aires: Depalma.

Palacio, L.E. (2004). Los deberes de lealtad, probidad y buena fe en el proceso civil. En Córdoba, M. M. (coord.) Tratado de la buena fe en el Derecho (1ra ed., pp. 811-820). Buenos Aires: La Ley.

Piaggi, A.I. (2009). Reflexiones sobre dos principios basilares del Derecho: la buena fe y los actos propios. En Córdoba, M. M. (coord.) Tratado de la buena fe en el Derecho (1ra ed., pp. 105130). Buenos Aires: La Ley.

Presno Arturo, M. y M. Ramos Palermo (2016). Trascendencia de los vicios formales en la jurisprudencia tributaria del Tribunal de lo Contencioso Administrativo. Montevideo: La Ley Uruguay.

Rodrigues, I.T. (2003). O princípio jurídico da boa-fé e o planejamento tributário o pilar hermenêutico para a compreensão de negócios estruturados para obter economia tributaria. Revista Dialética de Direito Tributário, (93).
Rodrigues, M.S. (2007). O princípio da boa-fé no Direito Tributário. San Pablo: Magíster.

Rubinstein, F. (2009). Boa-fé objetiva no direito financiero e tributário. San Pablo: Quartier Latin.

Sabariz Núñez, G. (2017). Daños por afectación del "derecho al duelo calmo" ante una autopsia falsa: una condena al Poder Judicial por violación de derechos fundamentales. La justicia uruguaya: revista jurídica, (155).

Sepinuck, S.L. (2018). The various standards for the good faith of a purchaser. The Business Lawyer, 73 (3), pp. 581-626.

Spolansky, N.E. (1969). La estafa y el silencio. Buenos Aires: Editorial Jorge Alvarez.

Torres, H.T. (2015). Boa-fé e confiança são elementares no Direito Tributário. En Brigagão, G., Torres, H. T., Santiago, I. M. \& R. D. Estrada (coords.), Consultor Tributário: Estúdios Jurídi$\cos$ (pp. 221-231). Rio de Janeiro: Topbooks.

Van Rompaey, L. (2000). Reflexiones sobre los princípios generales de derecho. Anuario de Derecho Civil Uruguayo, (XXX).

Véscovi, E.E. (1958). La regla moral en el proceso civil. Revista de Derecho, Jurisprudencia y Administración, 56 (6-8), pp. 174-

(1992-1993). Código general del proceso: comentado, anotado y concordado (tomos 1 y 2). Montevideo: Editorial Abaco.

Yersin, D., Pistone, P., Gutmann, D \& Y. Noël (eds.) (2007). Commentaire Romand: Impot Fédéral Direct. Basilea: Helbing \& Lichtenhahn.

Zarini, H.J. (2016). Fiscalización y verificación en la Ley 11.683. Práctica y Actualidad Tributaria, (XXII).

\section{LEGISLACIÓN, JURISPRUDENCIA Y OTROS DOCU- MENTOS LEGALES}

Constitución de la República Italiana [Const.] (1947). Recuperado de http://www.ces.es/ TRESMED/docum/ita-cttn-esp.pdf (1947)

Convención Americana sobre Derechos Humanos de la Organización de los Estados Americanos, del 22 de noviembre de 1969.

Corte Suprema de Justicia de la Nación Argentina [Argentina]. Fallos 312:1725, de 21 de setiembre de 1989. 
Decreto 500/991. Aprobación del Procedimiento Administrativo y Disciplinario Aplicable al Funcionario Público de la Administración Central. Diario Oficial, 27 de setiembre de 1991.

Decreto Ley 14.306, que aprueba el Código Tributario 14306. Diario Oficial, 29 de noviembre de 1974.

Ley 18.788, Ley de Relacionamiento de los Contribuyentes con la Administración Tributaria. Diario Oficial, 19 de agosto de 2011.

Ley 58/2003, Ley General Tributaria. Agencia Estatal Boletín Oficial del Estado, 18 de diciembre de 2003.
Tribunal de apelaciones civil de segundo turno [Uruguay]. Sentencia inédita de 5 de marzo de 2016.

Sentencia 831/2012, de 26 de marzo de 2013.

Sentencia 256/2013, de 2 de mayo de 2013.

Sentencia 391/2014, de 30 de setiembre de 2014 .

Sentencia 287/2015, de 14 abril de 2015 .

Sentencia 507/2014, de 14 abril de 2015 . 